\title{
ORIGENS HISTÓRICAS DA CIDADE DE BRAGANÇA.
}

\author{
HERALDO MAUES \\ Licenciado em Historia pela Faculdade de Fllosofia da \\ Universidade do Pará. \\ I. - INTRODUÇÃO.
}

Bragança é, atualmente, o terceiro município do Estado do Pará em população. Pelo Censo de 1960 , possuia 69.005 habitantes. Em 1961, como desmembramento sofrido em consequiência da criação do município de Augusto Correia, passou a ter apenas 51.884. A cidade possui 19.401 habitantes, incluindo-se nêsse número a população urbana e rural.

Do ponto de vista econômico, sua situação não é das melhores. Foi no passado muito próspera, a ponto de já ter sido considerada a segunda cidade do Estado em importância. Esse progresso ela o deveu à fertilidade do solo, com a grande produção de tabaco, arroz e mandioca que apresentava o município. Outro fator de progersso foi a localização geográfica. Bragança está situada à margem esquerda do rio Caeté, próximo à foz, ficando a poucas horas de viagem da fronteira do Maranhão. Liga-se por terra com Belém, tanto pela Estrada de Ferro de Bragança (E.F.B.) como pela Rodovia PA-25. Durante muito tempo foi o ponto de passagem quase obrigatório dos produtos que circulavam entre o Pará e o Maranhão. Isso proporcionou-lhe um intenso movimento comercial, que contribuiu para o progresso.

Hoje, com a abertura das rodovias BR-14 (Belém-Braślia) e BR-22 (Pará-Maranhão), surgiram novos caminhos para essa ligação. Cidades como Castanhal e Capanema, nascidas ao longo da E.F.B., cresceram em importância, achando-se em franco progresso. Concretizando-se a ameaça de paralização da Estrada de Ferro, isso será um golpe ainda mais sério para a economia de Bragança.

Mas, assim mesmo, ela não perdeu todo o interêsse que antes tinha. Embora seu solo esteja cansado, o movimento do comércio 
bastante diminuido e o mercado de trabalho quase inexistente, Bragança apresenta aspectos sumamente sedutores.

Um dêles é a tradição.

Bragança é uma cidade profundamente tradiciond, com sua festa de São Benedito, onde a Marujada desempenha um papel tão importante no sentimento popular. Tem sido procurada por etnógrafos e folcloristas, que nela realizam importantes estudos. E' também de interêsse turístico, não só pela tradição, mas por suas belas paisagens.

E' uma das cidades mais antigas do Estado. Einbora sé tenha sido elevada à categoria de cidade em 1854, suas origens remontam aos primeiros tempos da colonização do Grão-Pará.

Nêste trabalho, procuramos sistematizar dados esparsos, objetivando fornecer uma visão tão completa quanto possível sôbre as origens históricas de Bragança até meados do século XVIII.

As fontes não são muitas, máxime quanto aos primeiros tempos. Não obstante, em autores clássicos da historiografia nacional, tais como Varnhagen e Rocha Pombo, encontram-se aigumas informações. Nos autores que se dedicam à história do Pará, especialmente Ernestro Cruz e Jorge Hurley, pudemos obter dados precinsos. A maior parte do material consultado, porém, encontra-se nos Anais da Biblioteca e Arquivo Público do Pará: trabalhos de Artur Viana, Palma Muniz, Barão de Guajará e, principalmente, a coleção de Cartas Régias e correspondência dos governadores do Pará com a Metrópole.

Acreditamos que o interêsse maior dêste estudo está no fato de acompanhar o surgimento e a evolução de uma cidade paraense em suas origens remotas. Como muitas outras no Brasil, ela foi de início a sede de uma capitania hereditária. Seguiu também o caminho de grande parte das atuais cidades da Amazônia: foi núcleo de missão jesuítica, tendo sofrido os benéficos influxos da administração de Mendonça Furtado.

Com êste trabalho, desejamos apresentar uma modesta contribuição no sentido de divulgar alguns aspectos pouco lembrados da história da Amazônia .

\section{II. - A COLONIZAÇÃO DO NORTE BRASILEIRO.}

A primeira tentativa de colonização do norte brasileiro foi feita logo após a repartição do Brasil em capitanias hereditárias. Em 1535 partiu de Portugal a expedição de Aires da Cunha, sócio de João de 
Barros e Fernão Âlvares de Andrade. Morrendo Aires da Cunha em águas do Maranhão, os expedicionários se estabeleceram na atual ilha de São Luís, a que deram o nome de Trindade. Nela fundaram a vila de Nazaré. Pouco depois, conflitos com os índios, a quem provàvelmente os portuguêses tentaram escravizar, fizeram fracassar essa primeira tentativa.

Em 1594 Jacques Riffault e Charles des Vaux, corsários franceses, estiveram nessà região, estabelecendo contato com os índios e dando início a um núcleo de colonização francesa. O primeiro voltou à França, com o objetivo de dar a notícia ao rei e obter amparo oficial. Como demorasse a voltar, des Vaux resolveu ir à pátria em pessoa. Só em 1612 é que chegou ao Maranhão o fidalgo Daniel de la Touche, Senhor de La Ravardière, visando incrementar a colonização iniciada .

A essa época os franceses vinham sendo aos poucos repelidos do território que, pelo Tratado de Tordesilhas, deveria pertencer aos portuguêses. Estabelecidos no Maranhão, êles voltavam os olhos para a foz do Rio das Amazonas, sôbre o qual se contavam lendas excitantes, prometedoras de grandes riquezas aos seus exploradores. Diz Salm de Miranda:

"A expedição de la Ravardière era o lance inicial de um vasto plano de conquista da bacia amazônica" (1).

Já estabelecidos em terras da Guiana, os franceses poderiam, partindo dali para o sul e do Maranhão para o norte, estender suas conquistas, no sentido de dominar todo o litoral da atual Amazônia brasileira.

Assim é que, a 8 de julho de 1613, Ravardière,

- "com uma fôrça de quarenta praças, dez marinheiros e vinte principais tupinambás, deixou o Maranhão, sob salva de artilharia do forte de São Luís, num pequeno navio do comando de Charles des Vaux, com o objetivo de fundar uma colônia no Pará" (2).

Um dos pontos por onde passou Ravardière foi uma aldeia de índios tupinambás, situada à margem do rio Caeté. Provàvelmente foi essa a aldeia que, no futuro, daria origem à cidadc de Bragança . Nela teria passado um mês, retirando-se a 17 de agôsto (3).

(1) - - Miranda (Salm), Expansāo para o Norte, pág. 42.

(2). - Hurley (Jorge), Noçōes de História do Brasil e do Pará, pág. 50.

(3). - Até certo ponto, parece-nos exagêro aftrmar que tenha passado um mês nessa aldeia. E' possivel porém que tencionasse fundar all um estabelecimento mais durável. Náo tivemos acesso a documentos originals. A informação é de Hurley, op. cit., pág. 50. 
Uma antiga tradição refere que os franceses atribuiram o nome de Benquerença a essa aldeia indígena, por motivo de se terem agradado do local e também das boas relações que mantiveram com os índios (4). Não sabemos se se pode dar crédito a essa tradição. $O$ certo é que os bragantinos ainda hoje a repetem.

Após a passagem dos franceses pelo rio Caeté, duranta certo tempo essa região esteve sem receber a visita de nenhum europeu. Só no ano de 1616 é que se tem notícia da passagem de Pedro Teixeira, possivelmente pela mesma aldeia visitada por Ravardière.

Com a expulsão dos franceses do Maranhão, em 1615, foi designado Castelo Branco para dar início ao estabelecimento português na foz do Amazonas. Guiado por Charles des Vaux, Castelo chegou ao local onde hoje existe a cidade de Belém, fundando o Forte do Presépio, a 12 de janeiro de 1616. A importância ta fundação de Belém para a conquista da Amazônia pelos portuguêses não merece dúvidas. Tratava-se do primeiro núcleo de colonização portuguêsa, a partir do qual se iria travar uma luta incessante contra os índios, contra os estrangeiros, contra a selva. Tratava-se do núcleo de onde irradiaria a colonização, de onde haveriam de partir as primeiras "tropas de resgate", de onde sairiam as primeiras expedições à cata das "drogas do sertão", onde teria início a catequese. $\mathrm{E}$, mais ainda, onde começaria a preparação da viagem de Pedro Teixeira, o maior bandeirante da Amazônia que, em 1637, saindo de Cametá, contribuiu decisivamente para a efetivação dessa conquista.

Logo após a fundação de Belém, êsse mesmo Pedro Teixeira foi incumbido de levar a notícia ao governador do Maranhão, pedindo reforços. A viagem se fêz por terra: foi a primcira entrada do grande bandeirante. Era auxiliado pelo Alferes Antônio da Costa. Levava consigo 2 soldados e 30 tupinambás, sendo guiado por êstes, profundos conhecedores do sertão. Saindo de Belém, Teixeira subiu rio Guamá, passou pelo sítio que no futuro seriam Durém e Bragança, até "sair na costa junto ao Turiaçu", donde prosseguiu no caminho de São Luís (5). Não se pode afirmar que o bandeirante tenha passado pelo lugar onde hoje se ergue a cidade de Bragança. Entretanto, pelo que informa Baena em seu "Compêndio das Éras", é certo que passou pelo Caeté, pois os índios dêsse rio chegaram mesmo a tentar matá-lo na passagem (6) .

(4). - Pereira (Cesar), Mani de Urutá, pág. 5. Fol o mesmo César Pereira quem, pessoalmente; relatou-nos essa tradiçáo. Vide também IBGE: Bragança, n’' 179 da Coleçăo de Monografias, pág. 4.

(5) . - A indicaçâo do caminho seguldo por Pedro Telxeira se pode encontrar em Cruz (Ernesto), História do Para. 29 vol., pág. 646.

(6). - Vide Varnhagen, História Geral do Brasil, 29 tomo do 19 vol., pág. 149. 
A viagem de Pedro Teixeira inaugurou um camiriho, em parte fluvial, em parte terrestre, que provàvelmente a princípio passava pelo território do atual município de Bragança e, segundo Capistrano (7), existiu até o século XIX. Não se tratava mais, exatamente, do mesmo caminho. Ainda hoje existe sua lembrança entre os habitantes de Ourém, pois, até bem recentemente, êle servia para o transporte do gado vindo do Maranhão.

Segundo Ernesto Cruz, essa "estrada de Bragança" mereceu as atenções da colonização portguêsa em virtude dos grande perigos da navegação marítima entre o Pará e o Maranhão.

Diz também Artur Viana que a estrada tinha a finalidade estratégica de manter a ligação entre as duas capitanias, em caso de bloqueio que impedisse as comunicações marítimas (8).

Foi o governador Cristóvão da Costa Freire (1707-10) quem iniciou sua construção. Pouco depois, as obras foram paralizadas. Em 1720, o Ouvidor geral da capitania do Pará, Francisco Galvão da Fonseca, sugeriu ao rei sua continuação

$$
\begin{aligned}
& \text { "externando as conveniências dai resultantes à fazenda real e } \\
& \text { aos moradores de ambas as capitanias". }
\end{aligned}
$$

Pela Carta Régia de 31 de março de 1722 o rci ordenou ao governador João Maia da Gama (1722-28) que continuasse a estrada. Não se tratava mais do primitivo roteiro trilhado por Pedro Teixeira em 1616. E' o mesmo Artur Viana quem nos informa:

"A estrada para o Maranhão principiava na margem do rio Guamá, junto à segunda cachoeira, subindo, e seguia pelo centro procurando mais ou menos a linha divisória das águas dos afluentes do Tocantins, pela margem direita, e dos rios que correm para a costa norte" (9). leu

Maia da Gama conseguiu ver a estrada concluida, o que !he va-

$$
\begin{aligned}
& \text { "um louvor público do rei, exarado na Carta Régia de } 1^{\circ} \text { de } \\
& \text { março de 1725". }
\end{aligned}
$$

No ponto inicial da estrada foi construida, ainda no govêrno de Maia da Gama, a Casa Forte do Rio Guamá, origem da atual cidade de Ourém. Sua finalidade era ter-se ali

(7). - Citadō por Ernesto Cruz, op. cit., pág. 647.

(8). - Vlana (Artur), As Fortificaçסes da Amazbnia. T. - As Fortificaçס́es do Pará, Anais da Biblloteca e Arquivo Público do Pará, tomo 4\%, pág. 265.

(9). - Viana, op. cit., págs. 265 e 266. 


\begin{abstract}
"sempre prontas e equipadas, duas lanchas para levarem o expediente oficial que viesse do Maranhão ao Gumá",
\end{abstract}

Luís de Moura foi o construtor dessa fortaleza.

Segundo Hurley,

"em setembro de 1724 foi inaugurado o Correio Pará-Maranhão, partindo por terra de Ourém, que nêsse tempo ainda não estava fundada..." (10).

Sòmente em nossos dias, porém, com a abertura da Rodovia BR-22, é que se vai tornando efetiva essa ligação terrestre entre Belém e São Luís.

\title{
III. - DIVISÃO DO PARA EM CAPITANIAS.
}

Com a fundação de Belém, foi o Pará constituido em capitania da Corôa. Já a êsse tempo começavam a reverter a Corôa as donatarias com que se havia iniciado a colonização do Brasil.

Entretanto, a Metrópole havia resolvido dividir o Pará em capitanias hereditárias, seguindo a experiência antiga. Como diz Hurley, o Pará se afigurava na visão real como

\footnotetext{
"um mundo novo, um verdadeiro país que, para colonizar, era preciso dividir" (11).
}

A 25 de maio de 1622 Filipe III havia doado a Gaspar de Sousa, ex-governador geral do Brasil, uma capitania, com sítio a escolher, no território recentemente conquistado da Amazônia. Essa doação era feita em reconhecimento aos serviços prestades pelo ex-governador na conquista da costa norte.

Já desde 1621 que o território brasileiro havia sido dividido em dois Estados: o Estado do Brasil (do Rio Grande do Norte para o sul) e o Estado do Maranhão (do Ceará para o norte). O primeiro governador nomeado para o Estado do Maranhão foi Francisco Coelho de Carvalho. Houve delongas. A notícia só chegou a Belém em 1624. Finalmente, a 8 de setembro de 1626 é que o primeirc governador do nôvo Estado assumiu o govêrno.

Coelho de Carvalho, obedecendo às instruções que recebera, a 15 de abril de 1627 saiu de São Luís, num patacho e mais duas embarcações, com a finalidade de visitar o Pará. Passando pelo rio Gurupí; desembarcou, deixando-se entusiasmar pelto lugar, onde

(10). - Hurley (Jorge), Belém do Pará sob o domínio português, pág. 45.

(11). - Noçōes de História do Brasil e do Pará, pág. 339. 
estabeleceu os fundamentos da povoação a que chamou de Vera Cruz do Gurupí (12).

Ernesto Cruz refere que o governador prosseguiu sua viagem por terra até Belém. Teria seguido o caminho de Pedro Teixeira? Diz mais ainda que Coelho de Carvalho regressou a São Luís "pelo mesmo caminho". Levava consigo os colonos necessários para o povoamento de Vera Cruz. Esse fato é confirmado pelo memorial de Bento Maciel Parente, que também informa terem sido 60 os moradores que o governador levou para a nova povoação (13).

Por Alvará de 19 de março de 1624 Filipe III havia autorizado o governador do Estado do Maranhão a doar sapitanias. Coelho de Carvalho, entusiasmado, como estava, por aquêle empreendimento, resolveu constituir a capitania do Gurupí, que doou a seu filtho $\mathrm{Fe}-$ liciano Coelho de Carvalho. Essa foi a primeita capitania hereditária estabelecida no Estado do Maranhão.

A doação, porém, não foi confirmada pelo rei da Espanha. $O$ motivo é que, a 10 de outubro de 1633, Álvaro de Sousa, filho mais velho de Gaspar de Sousa, escolhendo o sítio da capitania doada ao pai em 1622, requereu as terras limitadas pelos rios Turiaçú t. Quatipurú. A capitania do Gurupí ficaria encravada nêsse território. A pretenção de Álvaro de Sousa foi atendida pela Carta Régia de 13 de fevereiro de 1634 .

Francisco Coelho de Carvalho procurou outro local estabelecendo, no Tocantins, a capitania de Cametá, e a 24 de dezembro de 1635 fundou a Vila Viçosa de Saanta Cruz de Cametá, sob a invocação de São João Batista. O trabalho dispendido por Coelho de Carvalho na fundação de Vera Cruz não ficou em vão, porquanto essa vila deu origem à atual cidade de Viseu.

Outras capitanias foram criadas no território paraense, tais como: a capitania do Cabo Norte, doada a Bento Maciel Parente, de alta significação estratégica em virtude das pretenções dos franceses, inglêses e holandeses de se apoderarem do território que é hoje o Amapá; a capitania da Ilha de Joanes (Marajó), doada a Antônio de Sousa Macedo, onde se desenvolveu a criação de gado; a capitania do Xingú, doada a Gaspar de Sousa Freitas; a capitania de Gurupá, que surgiu das ruínas do forte holandês de Mariocai, onde Maciel Parente edificou o forte de Santo Antônio de Gurupá (capitania da Corôa). Aos poucos, tôdas elas foram revertendo à Corôa, esgotados já esforços dos seus donatários na colonizaçăo.

\footnotetext{
(12). - Cruz, op. cit., pág. 734.

(13). - O memorial de Bento Maciel Parente fol enviado a Filipe III em 1630, sugerindo a criaçáo das seguintes capitanias subalternas: do Gurupí, do Marajó, de Cametá, a das llhas do Amazonas e a do Cabo Norte. (cone. Cruz, op. cit., pág. 734).
} 


\section{IV. - A CAPITANIA DO CAETE.}

Primitivamente chamou-se de capitania do Gurupí, nome dado por Coelho de Carvalho, tendo por sede a povoação de Vera Cruz.

São muito confusas as informações dêsses primeiros tempos.

Segundo Ernesto Cruz, não há prova documentada de que Álvaro de Sousa, donatário reconhecido pela Corôa, tenha promovido a transferência de sua sede de Vera Cruz do Gurupí para o rio Caeté (14). Ao que tudo indica, essa transferência de sede é que provocou a mudança do nome da capitania. Sousa

Rocha Pombo informa, no entanto, que o donatário Álvaro de "fundou a vila do Sousa do Caeté, mais tarde (1753) Bragança" (15).

Examinando essa informação, Ernesto Cruz conclui:

"Ao tempo de Álvaro de Sousa, o que existia era a povoação de Vera Cruz do Gurupi, que Francisco Coelho de Carvalho doou a seu filho, com o nome de Capitania do Gurupí..." (16).

Outros, porém, afirmam que foi Alvaro de Sousa quem fundou a povoação de Sousa do Caeté. Não sabemos se simplesmente copiaram a informação de Rocha Pombo, ou se se basearam emı outras fontes.

Nova dúvida existe quanto à localização dessa vila. Várius autores, entre os quais Cruz, Hurley, Viana, deixam implícito ou explícito que Sousa do Caeté foi fundada à margem esquerda do rio Caeté, onde hoje existe a cidade de Bragança. E' o que se infere também da correspondência do governador Francisco Xavier de Mendonça Furtado com a Metrópole, quando trata da fundação da vila de Bragança à margem esquerda do Caeté.

Palma Muniz, porém, em Limites Municipais do Estado do Pará, diz explìcitamente:

"O donatário Álvaro de Sousa empreendeu desde logo o beneficiamento da sua capitania, que se estendia pelo sertão até 20 léguas. Promoveu a imigração para ela e fundou, na margem direita

(14). - Oruz, op. cit., pág. 737.

(15) . - Pombo( Rocha), História do Brasil, 5 e vol., pág. 7 (conf. Cruz, op. cit., págs. 737 e 741).

(16). - Cruz, op. cit., pág. 740 . 
do rio Caeté, a uns 800 metros abaixo da atual cidade de Bragança, um núcleo colonial, cuja sede se chamou Sousa do Caeté" (17). afirma:

Essa também é a versão apresentada por Augusto Correia, que

"Álvaro de Sousa, procurou então desenvolver essa capitania, transferindo a sede de Vera Cruz, para a margem direita do rio Caeté, a 10 milhas mais ou menos de sua foz, fundando a vila, que denominou Sousa do Caeté ... Esse lugar é hoje conhecido por Vila-Cuera" (18).

Quando da comemoração do $10^{\circ}$ centenário da elevação de Bragança à categoria de cidade, durante a gestão do prefeito César Pereira, foi erguido em Vila-Cuera um monumento comemorativo ao fato. A tradição conserva Vila-Cuera como tendo sido a primitiva sede da capitania do Caeté. De qualquer modo, persiste a dúvida sôbre a localização da Vila do Sousa.

Tendo ou não sido fundada por Álvaro de Sousa, na margem esquerda ou direita, o certo é que Sousa do Caeté foi a origem mais remota da atual cidade de Bragança.

Como vimos, a sede da capitania tinha sido transferida de Vera Cruz do Gurupí para o rio Caeté, vila do Sousa .

Segundo Ernesto Cruz (19) o motivo da transferência foi a fertilidade do solo das margens do Caeté e ainda mais a possibilidade da existência de minas de prata a explorar.

Não se pode afirmar se Álvaro de Sousa chegou a visitar sua capitania. E' provável que não. Sabe-se, porém, que nomeou João de Herrera da Fonseca como capitão-mor e seu lcco-tenente. A transferência da sede da capitania deve ter-se realizado durante sua gestão; o nome - Vila do Sousa - era possivelmente uma hcmenagem ao donatário. Refere o Pe. José de Morais, na sua História da Companhia de Jesus (20), que a capitania foi progredinde com a transferência de uma grandiosa aldeia da nação apotianga, descida das margens do Piriá pelo jesuíta Bento Álvares:

"sendo capitão-mor e loco-tenente por parte do donatário João de Herrera da Fonseca e dos moradores que passaram do Gurupi se formou a vila".

\footnotetext{
(17). - Anais, tomo 8\%, pág. 269.

(18). - Correia (Augusto), Monografia Histórico-Corográfica do Municipio ae Bragança, fls. 1 (trabalho mimeografado).

(19). - Cruz, op. cit., pág. 736.

(20). - Citado por Cruz, op. cit., pág. 736 .
} 
Na coleção de Cartas Régias publicada pelos Anais da Biblioteca e Arquivo Público do Pará há diversas informações com respeito à capitania do Caeté. Sousa

Sabe-se assim que em 1644 o rei passou um Alvará a Álvaro de

\begin{abstract}
"para que o governador e Capitão mor do Pará lhe não impedisse trazer gentio e Aldeias para a dita Capitania".
\end{abstract}

Em 1648 foi passado outro Alvará ao mesmo Âlvaro de Sousa

"para se lhe restituir o gentio que se tinha ausentado com a entrada dos Holandeses e se lhe não retirar mais dali por diante".

Essas informações se encontram na Carta Régia de 11 de fevereiro de 1730 (21). Por ela se sabe também que Manoel de Melo, filho de Álvaro de Sousa, obtivera do rei uma ordem ao

\footnotetext{
"superior das Missões que os Indios da dita Aldeia deviam estar a sua ordem e das suas justiças no que respeitava à jurisdição temporal...".
}

Essa Carta Régia tinha sido motivada por reclamação do neto de Álvaro de Sousa, o Porteiro-mor do Reino José de Melo e Sousa que, por sua vez, pleiteava o govêrno temporal dos índios, deixando-se o espiritual a cargo dos missionários. Pedia também autorização para introduzir na sede da capitania 200 casais de indígenas.

Pelas informações dessa Carta, podemos concluir que o sucessor de Álvaro de Sousa teria sido, possivelmente, seu fillho Manuel de Melo. O Porteiro-mor do Reino José de Melo e Sousa, neto do $10^{\circ}$ donatário, substituiu o pai na posse e no govêrno da capitania. Desde o início da colonização o trabalho indígena era muito necessário. Já havia inclusive conflitos entre a administração temporal e os missionários, em tôrno do problema do indígena.

Encontram-se também outras referências ao donatário José de Melo e Sousa. Tratam-se de mais duas Cartas Régias enviadas ao governador do Estado do Maranhão e Grão-Pará. Através dêsses documentos, podemos ter uma idéia do que era a vida dos moradores da capitania.

Na Carta Régia de 4 de fevereiro de 1734 temos a cópia da seguinte petição endereçada ao rei de Portugal:

"Diz o Porteiro-mor José de Melo e Sousa que êle, por doação que V. Magestade houve por bem confirmar, é Donatário da Aldeia de Caeté, Estado do Maranhão, a qual, sendo algum tempo muito

(21). - Anais, tomo 3ং, págs. 284 a 285. 
populosa, se acha hoje quase despovoada, e para se conservar e não ficar de todo sem moradores, necessita o suplicante de gue $\mathrm{V}$. Magestade se sirva dar faculdade para que cada um dos que a habitarem possam a sua custa resgatar de qualquer sertão cinquenta casais de gentios, dando-se para isto Indios remeiros das Aldeias de V. Magestade, por serem poucos os que há na Aldeia e preciosos todos para remédio dos moradores, motivo pelo qual se faz preciso que os Governadores do Estado não tirem gentios da dita Aldeia para serviço algum..." (22).

Em síntese, noutro tempo, talvez na época da administração de João de Herrera da Fonseca, a capitania prosperava. Em 1734, porém, seus habitantes não só tinham de obter permissão para resgatar 50 casais do gentio, como também não deveriam os governadores do Estado usar o serviço dos já existentes na capitania. O pedido também indica a necessidade de obter vantagens no tocante à escravização do índio, aos que fôssem habitar a capitania, a fim de atrair novos moradores. Era a decadência.

Não se sabe ao certo quem foi nomeado loco-tenente do donatário em substituição a João de Herrera da Fonseca. Há referência porém a um certo Manuel de Sousa, nomeado capitão-mor por José de Melo e Sousa, certamente para tentar revigorar a capitania. A nomeação deve ter sido feita por volta de 1730 .

Mas o governador do Estado do Maranhão não tomou conhecimento da carta de nomeação lavrada por José de Melo, pelo que êste protestou junto ao soberano. A reclamação provocou a Carta Régia de 17 de fevereiro de 1734, onde o rei ordenava ao governador que informasse as razões do seu procedimento (23) .

Aesar da presença de Manuel de Melo a povoação não pôde progredir. Pouco depois, durante o govêrno de Mendonça Furtado (1751 a 1759), a capitania reverteu à Corôa .

\section{V. - A FUNDAÇÃO DE BRAGANÇA.}

Segundo a tradição, os primitivos povoadores da cidade de Bragança foram os índios caetés, ramo dos tupinambás. Sua taba ficava onde hoje se acha o bairro da Aldeia (24).

Existe também uma interessante tradição com respeito ao nome da cidade. O nome - Bragança - teria sido dado à Vila do Sousa pelo próprio donatário da capitania, em 1640, data da libertação portuguêsa do domínio espanhol, em homenagem à nova casa rei-

(22) . - Anais, tomo 69, pág. 220.

(23). - Anais, tomo 60, pág. 230.

(24). - Anais, tomo 8\%, pág. 269. Vide também Cesar Pereira, op. cit., pág. 6. 
nante. Não há nenhum documento que confirme essatradição. A carta de Mendonça Furtado, de 11 de outubro de 1753, serve apenas para contestá-la. Nela Furtado diz claramente:

\begin{abstract}
“... me pareceu que não devia perder tempo em povoar as poucas palhoças que até agora se conhecia pela Vila do Caeté ou de Sousa, fundando naquêle importante e útil sítio uma populosa vila que faço tenção (sendo V. Magestade servido) fundar com o nome de Bragança".
\end{abstract}

De qualquer modo, porém, creio que se pode afirmar ser o nome dado em homenagem à dinastia reinante em Portugal, a mesma que conseguiu a independência do jugo espanhol.

Sabemos que em 1751 havia uma missão jesuitica na capitania. E' quase certo mesmo que essa missão tenha sido fundada desde os tempos de Álvaro de Sousa. Essa informação sôbrc o ano de 1751 nos é referida pelo Barão de Guajará no seu trabalho sôbre a Catequese dos Índios do Pará (25). Por ela se infere que a aldeia do Caeté estava despovoada e em precárias condições.

Nêsse ano começou o govêrno de Francisco Xavier de Mendonça Furtado, irmão do Marquês de Pombal. Por essa época.

\footnotetext{
"passou a Amazônia a ter ascendência sôbre o Maranhão, tendo sido transferida, de São Luís para Belém, a Capital do Estado, cuja denominação deixou de ser "do Maranhão e Grão-Pará" para tornar-se inversa, isto é, "do Grão-Pará e Maranhão" (26).
}

Esse foi um dos períodos mais fecundos da adninistração colonial portuguêsa na Amazônia, infelizmente ainda tão mal estudado.

Mendonça Furtado foi o fundador da vila de Bragança. Pela carta de 11 de outubro de 1753 (27) êle dá informações ao rei com respeito ao seu estabelecimento, referindo todos os planos que tinha em mente.

O governador havia recebido, pouco tempo antes, uma leva de colonos açorianos, com a missão de distribuí-los pelos pontos mais propícios, para que pudessem trabalhar em terras próprias. Recebera também ordens da Secretaria de Estado para inciorporar à Corôa as terras pertencentes a alguns donatários. Por essa altura o sistema de capitanias hereditárias já não era eficiente e estava entravando a colonização.

Numa visita que fêz à região do Salgado, encontrando a vila do Sousa em grande decadência, resolveu-se a revigorá-la. Havia

(25). - Anais, tomo 2\%, pág. 133.

(26). - Silva (Luís Osiris da), A Luta pela Amazônia, pág. 44.

(27). - Anais, tomo 2\%, pág. 53. 
boas razões para isso. Uma das mais importantes era a existência de salinas no litoral que, se exploradas de modo conveniente, poderiam render muito ao tesouro real. Ao governador o lugar parecera de grande importância. A decadência, êle o atribuiu às constantes desavenças entre colonos e missionários, em tôrno do aproveitamento do trabalho do índio. Tencionava ali fundar uma populosa vila, com o nome de Bragança.

Como encontrasse dificuldades em mandar mantimentos aos povoadores, Mendonça Furtado ordenou fazer-se duas grandes roças, por conta da Fazenda Real. Nelas se devia plantar bastante maniva (mandioca) e os legumes que fôsse possível.

Mandou também construir casas para alojar us novos moradores.

A dificuldade de comunicação marítima entre Belém e Bragança era grande. Por isso, Mendonça Furtado planejava ligar a nova vila a Ourém, recentemente fundada, por êle próprio, na Casa Forte do Rio Guamá. A comunicação deveria aprovsitar um braço do Caeté que quase se comunica com o Guamá. Dêsse braço partia um caminho terestre, conduzindo ao rio Guamá, "sòmente com pequeno trabalho de sete ou oito horas" de viagem. Colocaria alguns casais de colonos no pôrto do Caeté, aparelhados com canoas. Faria também alargar o caminho terestre, transformando-o numa bod estrada. Assim, os moradores de Bragança ficariam livres dos perigos do mar, transportando todos os seus gêneros com grande facilidade pelo dito rio Guamá até Belém.

O entusiasmo de Mendonça Furtado transparece claramente através do relato que faz. O sítio de Bragança cra "fertilíssimo", próximo ao Oceano, rico em peixes e caça, com grandes possibilidades de se extrair sal na costa,

$$
\begin{aligned}
& \text { "de sorte que se não veja na grande necessidade dêste gênero, } \\
& \text { em que agora se acha". }
\end{aligned}
$$

Já nas cartas de 10 e 13 de setembro de 1754 Mendonça Furtado informa, detalhadamente, sôbre como se procedeu a fundação de Brangança (28).

Antes de sua fundação, a Vila do Sousa estava reduzida a cinco ou seis palhoças. Foi encarregado o próprio Ouvidor geral de conduzir os povoadores da vila nova de Bragança. Este encontrou os maiores obstáculos da parte do jesuíta que dirigia a minssão indígena. As razões, são fáceis de inferir.

(28). - Anais. A carta de 10 de setembro está publicada às págs. 161,162 e 163 do 49 tomo. A de 13 a pág. 219 do $3^{\circ}$ tomo. 
Por essa época os missionários, principalmente jesuítas, eram acusados de se estarem aproveitando de sua condição de religiosos para obterem vantagens temporais. No trabalho do Barão do Guajará, citado linhas acima, pode-se ter uma idéia do que eram essas acusações. O próprio autor lamenta o fato de que os discípulos do Padre Vieira tivessem desvirtuado tanto sua missăo. Só pensavam em tirar proveito material das riquezas da terra, explorando o trabalho dos índios.

Esse é um tema sujeito a controvérsias. Não pretendemos nos alongar sôbre êle. $O$ certo, porém, é que não se pode esquecer o imenso serviço prestado pelos missionários, não só no aspecto religioso, com a catequese, mas também no aspecto político e econômico, contribuindo, como contribuiram, decisivamente, para a conquista da Amazônia pelos portuguêses.

Pouco depois seriam os jesuítas expulsos do Brasil, por ordem do Marquês de Pombal. Em 1753 os ânimos já estaram acirrados. Talvez isso explique em parte as dificuldades colocadas pelo jesuíta de Sousa do Caeté ao irmão de Pombal.

Pelo que diz Mendonça Furtado, quando o missionário viu que a vila seria restaurada, tentou por todos os meios impedí-lo. Chegou até mesmo a insultar o Ouvidor geral que se achava assistindo aos trabalhos de construção da estrada ligando Bragança a Ourém.

Por causa disso, o governador mandou colocar na vila uma guarda militar sob as ordens do Tenente Inácio de Castro Sarmento. Visava êsse destacamento, além da manutenção da ordem, providenciar também a arrecadação dos dízimos do pescado e das salinas lá existentes.

Com relação às salinas, Furtado mostra-se bastante otimista Refere que, no ano anterior (1735), só o padre missionário tirou mil alqueires de sal do sítio chamado Apeú. Esse sal foi vendido pelo preço de dez a doze tostões cada alqueire. As salinas,

\footnotetext{
"postas em ordem, poderão ser de grande utilidade assim à Fazenda Real como a tôda esta Capitania, tendo dentro dela êste gênero do qual se acha presentemente maior necessidade".
}

Com efeito, o entusiasmo do governador era plenamente justificável quanto à fundação da vila nova de Bragança. Basta referir um exemplo. Em 1753 os dízimos da vila foram arrematados pelo preço de oito mil réis. Em 1759, o governador Manuel Bernardo de Melo e Castro, sucessor de Mendonça Furtado, informava:

"os dizimos... se arrematarão pelos ditos dois anos de 1759 e 1760 por preço de cem mil réis..." (29).

(29). - Anais, tomo 8\%, pág. 74. 
Um acréscimo de noventa e dois mil réis, portanto. Isso nos pode dar uma idéia do progresso de Bragança durante o govêrno do irmão do Marquês de Pombal.

\section{VI. - CONCLUSÕES.}

De tudo o que foi visto anteriormente, podemos tirar as seguintes conclusões:

Foram os franceses, chefiados por Ravardière, os que primeiro visitaram o atual município de Bragança (1613), entrando em contáto com uma tribo de índios tupinambás estabelecida à margem do rio Caeté.

Mais tarde, em 1616, Pedro Teixeira também esteve no território do município de Bragança, sendo inclusive hostilizado pelos índios da aldeia do Caeté.

$O$ caminho aberto por Pedro Teixeira foi a primeira estrada ligando o Pará ao Maranhão, tendo sido posteriormente abandonado, em parte, procurando-se um roteiro mais propício a essa ligação.

No govêrno de Maia da Gama (1722-1728) é que foi concluida a ligação terrestre entre as duas capitanias; no entanto, já não passava por Bragança. Esse caminho existiu até o século XIX, para ser, em nossos dias, substituido pela Rodovia BR-22.

A origem mais remota de Bragança deve ter sido a aldeia indígena dos tupinambás, estabelecida à margem esquerda do Caeté.

Nêsse mesmo local, ou na margem direita, um pouco mais para a foz (onde hoje está Vila-Cuera), foi fundada a Vila do Sousa (provàvelmente na $4 \mathrm{a}$. década do século XVII), que se transformou na sede da capitania do Caeté. Essa capitania pertencia ao donatário Álvaro de Sousa, filho do ex-governador geral do Brasil Gaspar de Sousa.

Possìvelmente Âlvaro de Sousa nunca estêve em sua capitania, mas nomeou João de Herrera como loco-tenente. A instalação da vila do Sousa deve ter-se realizado durante sua administração. Bem cêdo instalou-se ali também uma missão jesuítica, tendo sido transferida uma tribo do Piriá(apotiangas), para aquêle 1ncal, pelo jesuíta Bento Alvares.

Os sucessores de Âlvaro de Sousa foram Manuel de Melo, seu filho, a José de Melo e Sousa, seu neto; êste, desempenhava o cargo de Porteiro-mor do Reino e nomeou como loco-tenente a Manuel de Sousa, que estêve na capitania durante a quarta década do século XVIII.

O aproveitamento da mão-de-obra indígena era muito importante para os colonos, havendo necessidade de resgatar muitos índios 
no sertão. Por êsse motivo, desde cêdo registraram-se conflitos entre colonos e jesuítas.

A capitania reverteu à Corôa durante o govêrno de Mendonça Furtado (1751-1759); encontrava-se em franca decadência, talvez em consequiência dos constantes conflitos entre missionários e colonos.

Mendonça Furtado foi o fundador da vila de Bragança (1753), no local da antiga vila do Sousa, que se achava reduzida a algumas palhoças. O nome - Bragança - parece ter sid J uma homenagem à casa reinante em Portugal, a mesma que libertara o país do jugo espanhol em 1640 .

Os primeiros colonos a habitarem a vila nova de Bragança foram açorianos, recentemente vindos das ilhas.

Nos primeiros tempos, havia muitas condições para o progresso da nova vila: solo fértil, salinas nolitoral, relatıvamente fácil a ligação com Belém. Esse progresso é atestado pelo aumento de 92 mil réis na arrecadação dos dízimos no período de 1753 a 1759 .

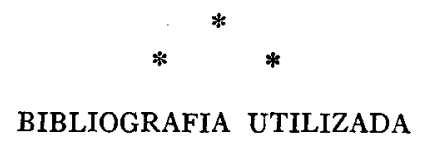

ANAIS DA BIBLIOTECA E ARQUIVO PÚBLICO DO PARÁ.

CORREIA (AUGUSTO), Monografia Histórico-Corográfica do Municipio de Bragança, Bragança, 1941 (mimeografado).

CRUZ (ERNESTO), História do Pará. Universidade do Pará, Belém, 1963.

HURLEY (JORGE), Noções de História do Brasil e do Pará, in Vol. XI da Revista do Instituto Histórico e Geográfico do Pará, Belém, 1938.

— Belém do Pará sob o dominio português, Livraria Clássica, Belém, 1940.

IBGE, Bragança, $\mathrm{n}^{0} 179$ da coleção de monografias, 1958.

MIRANDA (SALM), Espansão para o norte, Biblioteca do Exército Editôra, Rio, 1946.

PEREIRA (CÉSAR), Mani de Urutá (conto caeteuára), Bragança, 1958.

VARNHAGEN, História Geral do Brasil. Companhia Editôra Melhoramentos, São Paulo, 7a. Edição Integral, 1962.

SILVA (LUfS OSIRIS DA), A Luta Pela Amazônia. Fulgor, São Paulo, 1962. 